\title{
Oxygen Radicals and Arachidonate Metabolites in Lung Injury ${ }^{a}$
}

\author{
PETER A. WARD, KENT J. JOHNSON, \\ AND GERD O. TILL \\ Department of Pathology \\ The University of Michigan Medical School \\ Ann Arbor, Michigan 48109
}

There is an increasing amount of evidence that oxygen radicals produced by activated phagocytic cells play an important role in the induction of acute lung injury, which in some cases leads to progressive lung injury. The bulk of work in the past several years deals with models of acute lung injury in experimental animals. The findings of many of these studies have recently been extrapolated to considerations of the adult respiratory distress syndome (ARDS) in humans.

Oxygen radical production by activated phagocytic cells is now a well-known fact, ${ }^{1}$ and it is known that a variety of cells, such as neutrophils, eosinophils, monocytes, and macrophages, have the ability to produce oxygen radicals upon stimulation. There is more evidence that nonphagocytic cells may, under very special circumstances, also have the ability to produce oxygen radicals. ${ }^{2}$ There is little evidence, however, that either platelets or basophils can, upon activation with a variety of stimuli, generate these oxygen products, even though secretion of granule products is known to occur.

Oxygen radical production by phagocytic cells is stimulated by a variety of agonists. These agonists include chemotactic peptides and lipids; complement activation products such as anaphylatoxins and $\mathbf{C} 3 b$; phorbol myristate acetate; and phagocytic stimuli including immune complexes, zymosan particles, and other insoluble materials. Cell surface interaction with any of these agonists leads to a cascade of chemical reactions which appears to initially involve activation of a cell membrane associated NADPH oxidase. This results in the progressive reduction of molecular oxygen, by a sequential addition of electrons, to a series of products, as shown in the scheme below:

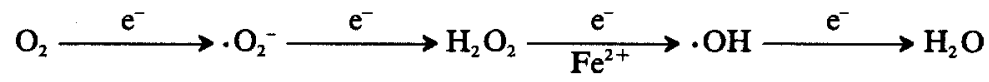

The sequential addition of four electrons to molecular oxygen ultimately results in the production of water. It is important to note that the intermediate oxygen radicals from the series described above are always present. The most unstable one is the hydroxyl radical $(. \mathrm{OH})$, the superoxide anion $\left(. \mathrm{O}_{2}^{-}\right)$is moderately unstable, and hydrogen peroxide $\left(\mathrm{H}_{2} \mathrm{O}_{2}\right)$ is very stable. It should be emphasized that the conversion of hydrogen peroxide to the hydroxyl radical is greatly facilitated by the presence of

\footnotetext{
${ }^{a}$ This work was supported in part by Grants GM18832, GM29507, HL28442, and HL31936 from the National Institutes of Health.
} 
ionic iron. It has been known for some time that in lipid peroxidation reactions iron plays a key role. ${ }^{3}$ Iron may be effective in these reactions because of its ability to facilitate the production of hydroxyl radical, although this is a controversial point at present. The recognition of a series of products appearing during the progressive reduction of molecular oxygen implies that in a given reaction at a given moment there will be a mixture of oxygen reduction products, which makes it difficult to implicate a single product in a reaction related to tissue injury. Evidence will be presented below that hydrogen peroxide and the hydroxyl radical may be the most important oxygen products that can be directly linked to tissue injury.

\section{ARACHIDONATE PRODUCTS AND PHAGOCYTIC CELLS}

Activation of phagocytic cells by chemotactic factors or phagocytic stimuli usually leads to a cascade of reactions ultimately resulting in the production of metabolic products from arachidonic acid (FIG. 1). Receptor-ligand interaction on the surface

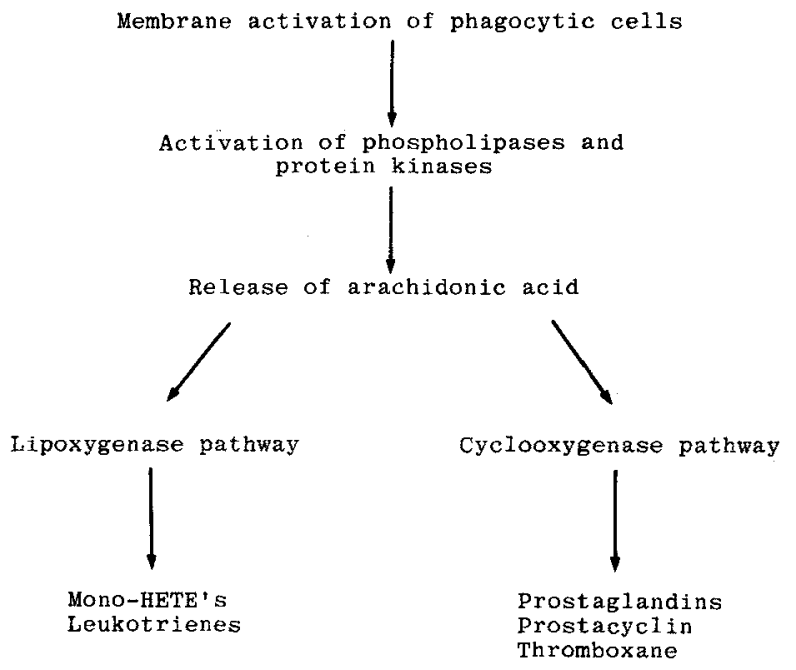

FIGURE 1. Arachidonate pathways in phagocytic cells.

of the phagocytic cell leads to activation of phospholipases, especially phospholipase $A_{2}$, which results in the cleavage of arachidonic acid from the second carbon position in the glycerol backbone of a phospholipid. There is some evidence that these reactions are also associated concomitantly with the activation of one or more protein kinases, which results in phosphorylation of lipomodulin, a naturally occurring inhibitor of phospholipases. The ultimate outcome of these reactions is the unrestrained activity of phospholipase $A_{2}$, which causes the appearance of free arachidonic acid within the cell. This fatty acid can then undergo metabolism by the cyclooxygenase and the lipoxygenase pathways. The former pathway results in the production of the classical 
prostaglandins and prostacyclin and thromboxane. The extent to which one or more classes of these cyclooxygenase products will be formed depends upon the cell type. In the neutrophil, for instance, large amounts of both classical prostaglandins (PGE $_{2}$ and $\mathrm{PGF}_{2 \alpha}$ ) and thromboxane $\left(\mathrm{TxA}_{2}\right)$ are formed, with little or no production of prostacyclin $\left(\mathrm{PGI}_{2}\right)$. In macrophages large amounts of prostaglandins are formed with little production of thromboxane. Metabolism of arachidonic acid via the lipoxygenase pathway results in the production of a series of mono-HETE compounds and often the simultaneous appearance of leukotrienes. Neutrophils tend to produce relatively large amounts of leukotriene $\mathbf{B}_{4}\left(\mathbf{L T B}_{4}\right)$ whereas macrophages tend to produce little in the way of $\mathrm{LTB}_{4}$ and large amounts of the sulfidopeptide leukotrienes $\mathrm{LTC}_{4}, \mathrm{D}_{4}$, and $E_{4} \cdot{ }^{4,5}$

The relationship between the appearance of these products of arachidonate metabolism and the functional response of the phagocytic cell is not very clear at present. Studies in different laboratories have produced conflicting results. The experimental approach has usually been either to measure the various arachidonate metabolites and correlate their presence with a functional response of the cell or to employ inhibitors, the specificity of which is often implied, in order to block either the lipoxygenase pathway or the cyclooxygenase pathway and to infer the role of products of each of these pathways in the functional response of the stimulated cell.

Our own studies on the production of arachidonate metabolites in stimulated rat neutrophils and the relationship of these products to the cell response are summarized in TABLE 1. Neutrophils were prelabeled with tritiated arachidonic acid which was fully incorporated into the phospholipid fraction. The cells were then stimulated with a variety of agonists: immune complexes, calcium ionophores, zymosan particles, chemotactic peptides, and phorbol myristate acetate. The cyclooxygenase inhibitors indomethacin, ibuprofen, and piroxicam, as well as the lipoxygenase inhibitors nordihydroguaiaretic acid (NDGA) and nafazatrom were employed. With reference to the specificity of these inhibitors (determined by high pressure liquid chromatography), it can be seen that the cyclooxygenase inhibitors reduced the generation of cyclooxygenase products between 40 and $50 \%$. The effectiveness of the different lipoxygenase inhibitors varied; the production of cyclooxygenase products was reduced between 1.4 and $25.8 \%$. When the effects of the same drugs on the generation of lipoxygenase products (chiefly 5-HETE and $\mathrm{LTB}_{4}$ ) were measured, it was found that the cyclooxygenase inhibitors substantially increased (32.5 to 83.2\%) the amount of leukotrienes produced, whereas the lipoxygenase inhibitors reduced (42.9 to $69.5 \%$ ) the amounts of 5-HETE and $\mathrm{LTB}_{4}$ formed. Based upon these data, it appears that cyclooxygenase products may "down-regulate" the lipoxygenase pathway; when the cyclooxygenase pathway is blocked, either through "substrate shunting" of arachidonic acid into the lipoxygenase pathway or via the loss of the negative feedback, there is a marked potentiation in the amount of lipoxygenase pathway products formed.

The effects of these inhibitors on the functional responses of rat neutrophils are summarized in TABLE 1. Oxygen radical production was reduced 15 to $43 \%$, and, a consistent pattern was demonstrated in the enzyme release response: cyclooxygenase pathway inhibitors enhanced it 14 to $18 \%$ whereas the lipoxygenase pathway inhibitors reduced it 28 to $78 \%$. These data can be interpreted to suggest that there is a linkage between lipoxygenase pathway product formation and enzyme secretion in activated rat neutrophils and that cyclooxygenase products tend to negatively affect this response. On the other hand, no such pattern has been noted with oxygen radical production. All inhibitors tend to have inhibitory effects, suggesting that there is a fundamental difference between the effects of arachidonate metabolites and their effects in the neutrophil responses of enzyme release and oxygen radical generation. These studies are described in detail in a recent report ${ }^{4}$ and are summarized in TABLES $2 \& 3$. 
TABLE 1. Relationship between Arachidonate Metabolite Production and Functional Responses in Stimulated Rat Neutrophils ${ }^{a}$

\begin{tabular}{|c|c|c|c|c|}
\hline \multirow[b]{2}{*}{$\begin{array}{l}\text { Inhibitor Employed } \\
\qquad(5-10 \mu \mathrm{M})\end{array}$} & \multicolumn{2}{|c|}{$\begin{array}{l}\text { Arachidonate Metabolites } \\
\text { (Percent Reduction) }\end{array}$} & \multicolumn{2}{|c|}{$\begin{array}{c}\text { Functional Responses } \\
\text { (Percent Reduction) }\end{array}$} \\
\hline & $\begin{array}{l}\text { Cyclooxygenase } \\
\text { Products }\end{array}$ & Leukotrienes & $\begin{array}{c}. \mathrm{O}_{2}^{-} \\
\text {Generation }\end{array}$ & $\begin{array}{l}\text { Enzyme } \\
\text { Release }\end{array}$ \\
\hline \multicolumn{5}{|l|}{ Cyclooxygenase inhibitors } \\
\hline Indomethacin & 50.6 & $-83.2^{b}$ & 15 & -14 \\
\hline Ibuprofen & 40.5 & -35.7 & 19 & -15 \\
\hline Piroxicam & 43.8 & -32.5 & 17 & -18 \\
\hline \multicolumn{5}{|l|}{ Lipoxygenase inhibitors } \\
\hline Nordihydroguaiaretic acid & 25.8 & 69.5 & & 78 \\
\hline Nafazatrom & 1.4 & 42.9 & 43 & 28 \\
\hline
\end{tabular}

${ }^{a}$ Neutrophils were stimulated with immune complexes of BSA and of rabbit IgG to BSA; this stimulation elicited the functional responses and production of arachidonates.

${ }^{b}$ Negative numbers indicate enhancement of cell response.

Some interesting parallels have been noted when arachidonate metabolite production is studied in rat neutrophils undergoing stimulation by a variety of different agonists. For instance, stimulation of rat neutrophils by phorbol myristate acetate leads to maximal $\cdot \mathrm{O}_{2}^{-}$generation but with only trivial amounts of arachidonic products being formed, whereas stimulation of rat neutrophils by the chemotactic peptide $N$-formyl-methionyl-leucyl-phenylalanine (FMLP) results in substantial enzyme release coupled with substantial arachidonate product formation but with virtually no . $\mathrm{O}_{2}^{-}$production. Again, these data suggest that there is a dissociation between $\cdot \mathrm{O}_{2}^{-}$ generation and enzyme release and that if arachidonate metabolites are directly involved in the cell response, it is in the enzyme secretion reaction but not in the response of $\cdot \mathrm{O}_{2}^{-}$generation.

Although macrophages in general tend to produce prostaglandins as well as the leukotrienes $\mathrm{C}_{4}, \mathrm{D}_{4}$, and $\mathrm{E}_{4}$, there is good evidence that a similar parallelism exists between cell activation and arachidonate product formation. ${ }^{5}$ In studies in mice in

TABLE 2. Neutrophil Activation, Functional Responses, and Arachidonate Metabolism

\begin{tabular}{|c|c|c|c|}
\hline \multirow[b]{2}{*}{ Agonist } & \multicolumn{2}{|c|}{ Functional Response } & \multirow[b]{2}{*}{ Arachidonate Metabolites } \\
\hline & $\begin{array}{c}\cdot \mathrm{O}_{2}^{-} \\
\text {Generation }\end{array}$ & $\begin{array}{l}\text { Enzyme } \\
\text { Release }\end{array}$ & \\
\hline $\begin{array}{l}\text { Phorbol myristate } \\
\text { acetate }\end{array}$ & Yes & Little & Few, if any \\
\hline $\begin{array}{l}\text { Chemotactic peptide } \\
\text { (FMLP) }\end{array}$ & No & Yes & $\mathrm{TxB}_{2}$, 5-HETE, and $\mathrm{LTB}_{4}{ }^{\sigma}$ \\
\hline Calcium ionophores & Little & Yes & Similar to those elicited by FMLP \\
\hline IgG-immune complexes & Yes & Yes & Similar to those elicited by FMLP \\
\hline
\end{tabular}


TABLE 3. Role of Arachidonate Metabolites in Functional Responses of Rat Neutrophils

\begin{tabular}{lcc}
\hline & \multicolumn{2}{c}{ Functional Response } \\
\cline { 2 - 3 } & $\begin{array}{c}\text { Enzyme } \\
\text { Secretion }\end{array}$ & $\begin{array}{c}\cdot \mathrm{O}_{2}^{-} \\
\text {Generation }\end{array}$ \\
\hline $\mathrm{O}_{2}^{-}$ & No correlation & - \\
$\begin{array}{l}\text { Enzyme secretion } \\
\begin{array}{l}\text { Production of arachidonate } \\
\text { metabolites }\end{array}\end{array}$ & - & No correlation \\
$\begin{array}{l}\text { Cyclooxygenase inhibitors } \\
\text { Lipoxygenase inhibitors }\end{array}$ & Correlation & No correlation \\
\hline
\end{tabular}

${ }^{*} \mathrm{PGE}_{2}, \mathrm{TxB}_{2}$, 5-HETE, and $\mathrm{LTB}_{4}$.

which $\mathrm{T}$ cell-dependent pulmonary granulomas have been investigated, it has been demonstrated that the in vivo application of lipoxygenase pathway inhibitors greatly diminishes granuloma formation whereas the treatment of animals with cyclooxygenase inhibitors of the type described above greatly increases the size of the granulomas. As might be expected, treatment of mice with prostaglandin $\mathbf{E}_{2}$ markedly diminishes the size of the granulomas. Although these studies have been confined to the mouse, the interpretation of the role of arachidonate metabolites is similar to that in the study of the rat neutrophil (described above). That is to say, cyclooxygenase pathway products tend to be inhibitory whereas lipoxygenase pathway products enhance the ultimate biological response of the activated neutrophil or macrophage.

\section{MODELS OF ACUTE LUNG INJURY DEPENDENT UPON OXYGEN RADICAL FORMATION}

Mediator pathways in models of acute lung injury in which oxygen radical formation appears to be importantly involved in the ultimate expression of lung injury have been studied in a variety of experimental model systems: these are summarized in TABLE 4. Three general classifications of model systems can be made. The first involves reactions in which neutrophils and complement are both required for the ultimate outcome. The second involves reactions in which complement is but neutrophils are not required for the development of tissue damage. The third involves a reaction in which neither complement nor neutrophil participation is required for acute lung injury.

Acute lung injury mediated by complement and neutrophils has been well demonstrated in the case of immune complex deposition involving immunoglobulin $G$ (IgG). Whether by the use of rabbit polyclonal antibody to bovine serum albumin (BSA) or mouse IgG monoclonal antibody to dinitrophenol (DNP), the resulting alveolar and vascular injury associated with deposition of immune complexes requires the availability of complement (presumably through its chemotactic factor C5a peptide and perhaps other neutrophil-activating products) and neutrophils ${ }^{6}$ which, through 
the formation of oxygen radicals, bring about acute tissue injury.' Superoxide anion which can be intercepted by the presence of superoxide dismutase (SOD) results in an amplification of the early phases of the inflammatory response, causing the accumulation of increased numbers of neutrophils at the site of the immune complex deposition. ${ }^{8}$ Additional studies have demonstrated that $\cdot \mathrm{O}_{2}^{-}$and $\mathrm{H}_{2} \mathrm{O}_{2}$ as well as iron participate in the outcome of immune complex-mediated tissue injury.' It is likely that iron is required because of its ability to facilitate conversion of $\mathrm{H}_{2} \mathrm{O}_{2}$ to. $\mathrm{OH}$. The basis for this conclusion is the recent demonstration that scavengers of hydroxyl radical as well as iron chelators will greatly attenuate the damage after IgG immune complex deposition in dermal vessels and lungs of rats. ${ }^{9}$ Leukocytic myeloperoxidase may also contribute to the development of injury through the conversion of $\mathrm{H}_{2} \mathrm{O}_{2}$ to a halide-dependent product such as hypochlorous acid; however, this has not been directly demonstrated in vivo.

The second model of acute lung injury involving the role of neutrophils and complement is that of systemic complement activation: injection of the $\mathrm{C} 3$ activator isolated from cobra venom into rats produces a prompt and profound activation of the complement system, which results in the stimulation of neutrophils and in the aggregation and entrapment of neutrophils within the pulmonary interstitial capillary network. Neutrophil activation with oxygen radical production results in the injury of, and sometimes causes the necrosis of, pulmonary endothelial cells. ${ }^{10}$ It has recently been demonstrated that the mechanism of injury is probably via hydroxyl radical formation; this seems likely because the endothelial cell damage can be greatly attenuated by the presence of catalase, hydroxyl radical scavengers (such as dimethyl sulfoxide), and iron chelators (apolactoferrin derived from human breast milk or deferoxamine). ${ }^{11}$

It has recently been demonstrated that another type of immune complex deposition leading to acute lung injury in rat follows a different immunopathogenic mechanism. The use of mouse monoclonal immunoglobulin A (IgA) antibody with reactivity to DNP has made it possible to demonstrate that immune complex deposition in rat lungs leads, in a manner in which neutrophils are not involved, to acute alveolar and vascular injury. The reaction, however, is clearly complement dependent. ${ }^{6}$ Evidence that this is an oxygen radical-related form of injury is emerging even though the source of the oxygen radical production has not been determined (K. J. Johnson, B. Wilson, and P. A. Ward, unpublished observations). It could be that IgA immune complexes acting through some complement activation product are causing oxygen radical production from alveolar macrophages, interstitial macrophages, and, perhaps, recruited blood monocytes. This remains to be demonstrated.

The third model system of oxygen radical-dependent acute lung injury involves a system that is both complement and neutrophil independent. Phorbol myristate acetate

TABLE 4. Model Systems of Oxygen Radical-dependent Acute Lung Injury

Neutrophil- and Complement-dependent Lung Injury

Acute immune complex injury by deposition of rabbit polyclonal IgG antibody to BSA or mouse monoclonal IgG antibody to DNP

Systemic complement activation by injection of $\mathrm{C} 3$ activator from cobra venom

Neutrophil-dependent and Complement-independent Lung Injury

Acute immune complex injury by deposition of mouse monoclonal IgA antibody to DNP

Neutrophil- and Complement-independent Lung Injury

Acute and progressive lung injury by instillation of phorbol myristate acetate 
instilled into the distal airways causes an intense and acute lung injury with the alveolar compartment being denuded of the epithelial lining cells. This results not only in acute injury with severe intraalveolar hemorrhage and edema but also in progressive pulmonary interstitial fibrosis. ${ }^{12}$ It has been demonstrated that neither complement nor neutrophil depletion will alter either the acute or the chronic outcome of this reaction. On the other hand, the coinstillation of catalase with phorbol myristate acetate will prevent both the acute and the progressive damage found in this model system.

The various experimental models described above suggest that oxygen radical production from activated phagocytic cells plays an important role in lung injury. Interventions designed to intercept these radicals are markedly protective. What determines chronicity and irreversibility of the lung responses in these models of injury is not known, but the observations to date have important implications in a variety of lung inflammatory reactions in humans, perhaps the most obvious example being the adult respiratory distress syndrome. Extensive additional studies will have to be completed before these reactions are fully understood and effective clinical therapeutic interventions are developed.

\section{REFERENCES}

1. FAnTone, J. C. \& P. A. WARD. 1982. Review article: Role of oxygen-derived free radicals and metabolites in leukocyte-dependent inflammatory reactions. Am. J. Pathol. 107: 395-418.

2. Freeman, B. A. \& J. D. Crapo. 1982. Biology of disease: Free radicals and tissue injury. Lab. Invest. 47: $412-426$.

3. Aust, S. D. \& B. A. Svingen. 1982. The role of iron in enzymatic lipid peroxidation. In Free Radicals in Biology. W. A. Pryor, Ed. Vol. 5: 1-28. Academic Press. New York, NY.

4. WARD, P. A., M. C. SulaviK \& K. J. Johnson. 1984. Role of lipoxygenase and cyclooxygenase products in neutrophil activation. Fed. Proc. 43: 1803.

5. KUnKel, S. L., S. W. Chensue, C. Mouton \& G. I. Higashi. 1984. Role of lipoxygenase products in murine pulmonary granuloma formation. J. Clin. Invest. 74: 514-524.

6. Johnson, K. J., B. S. Wilson, G. O. Till \& P. A. WARd. 1984. Acute lung injury in rat caused by immunoglobulin A immune complexes. J. Clin. Invest. 74: 358-369.

7. JohNSON, K. J. \& P. A. WARD. 1981. Role of oxygen metabolites in immune complex injury of lung. J. Immunol. 126: 2365-2369.

8. MCCoRmick, J. R., M. M. HARKIN, K. J. Johnson \& P. A. WARD. 1981. Suppression by superoxide dismutase of immune complex-induced pulmonary alveolitis and dermal inflammation. Am. J. Pathol. 102: 55-61.

9. Fligiel, S. E. G., P. A. WARd, K. J. Johnson \& G. O. Till. 1984. Evidence for role of hydroxyl radical in immune complex-induced vasculitis. Am. J. Pathol. 115: 375-382.

10. Till, G. O., K. J. Johnson, R. KunKel \& P. A. WARD. 1982. Intravascular activation of complement and acute lung injury: Dependency on neutrophilis and toxic oxygen metabolites. J. Clin. Invest. 69: 1126-1135.

11. Ward, P. A., G. O. Till, R. Kunkel \& C. Beauchamp. 1983. Evidence for role of hydroxyl radical in complement and neutrophil-dependent tissue injury. J. Clin. Invest. 72: 789-801.

12. Johnson, K. J. \& P. A. WARD. 1982. Acute and progressive lung injury after contact with phorbol myristate acetate. Am. J. Pathol. 107: 29-35. 